Accepted refereed manuscript of:

Dragouni M, Filis G, Gavriilidis K \& Santamaria D (2016) Sentiment, Mood and Outbound Tourism Demand, Annals of Tourism Research, 60, pp. 80-96.

DOI: 10.1016/j.annals.2016.06.004

(c) 2016, Elsevier. Licensed under the Creative Commons AttributionNonCommercial-NoDerivatives 4.0 International http://creativecommons.org/licenses/by-nc-nd/4.0/ 


\title{
SENTIMENT, MOOD AND OUTBOUND TOURISM DEMAND
}

\author{
Mina Dragouni ${ }^{1}$, George Filis ${ }^{2}$, Konstantinos Gavriilidis ${ }^{3 *}$, Daniel Santamaria ${ }^{4}$
}

\begin{abstract}
We investigate spillover effects from sentiment and mood shocks on US outbound tourism demand from 1996 until 2013. We use the Index of Consumer Sentiment and Economic Policy Uncertainty Index as proxies for sentiment and the S\&P500 as a proxy for mood. We find a moderate to high interrelationship among sentiment, mood and outbound tourism demand. More importantly, sentiment and mood indicators are net transmitters of spillover shocks to outbound tourism demand. The magnitude of spillover effects sourced by sentiment and mood is time-varying and depends on certain socio-economic and environmental events. Our results have important implications for policymakers and travel agents in their efforts to predict tourism arrivals from key origin countries and to plan their tourism strategy.
\end{abstract}

Keywords: Sentiment, mood, spillover effects, economic crisis, economic policy uncertainty, US JEL codes: C32, C51, L8

\footnotetext{
${ }^{1}$ University College London (UCL), Institute for Sustainable Heritage, The Bartlett, UCL Faculty of the Built Environment, Central House, 14 Upper Woburn Place, WC1H 0NN London, UK. Tel: 0044 (0) 2031 089040, Email: mina.dragouni.13@ucl.ac.uk

${ }^{2}$ Bournemouth University, Department of Accounting, Finance and Economics, Executive Business Centre, 89 Holdenhurst Road,BH8 8EB Bournemouth, UK. Tel: 0044 (0) 1202 968739, Email: gfilis@ bournemouth.ac.uk.

${ }^{3}$ University of Stirling, Stirling Management School, Stirling, FK9 4LA, UK. Tel: 0044 (0) 1786 467298, Email: konstantinos.gavriilidis@stir.ac.uk.

${ }^{4}$ Canterbury Christ Church University Business School, Canterbury, Kent CT1 1QU, UK. Tel 0044 (0) 1227767700 ext 3696, Email: daniel.santamaria@canterbury.ac.uk.

*Corresponding author
} 


\section{INTRODUCTION}

The economic implications of tourism in both origin and destination countries are highly important to society. For destination countries, this extends to government revenues, employment, infrastructure, broader socio-economic growth and diversification of economic activities (Li, Blake, \& Cooper, 2011). The importance of tourism is documented in the United Nations World Tourism Organization (2014) report, which shows that tourism contributes about 9\% of the global GDP and $\$ 1.4$ trillion of international exports. Tourism studies have adopted a multi-disciplinary approach integrating many social disciplines, including economics, in order to gain a better understanding of tourism related issues, such as tourism demand. This is reflected in the bulk of the research published on tourism demand determinants (Song, Dwyer, Li \& Cao, 2012).

Given the high importance of the tourism industry and its contribution to national economies and societies worldwide, the identification of factors that determine tourism demand behavior is critical for informing tourism management and policymaking. Indeed, there is a plethora of studies that focus their interest on the drivers of outbound tourism, which most commonly use macroeconomic variables, such as unemployment rate, gross domestic product and money supply (see, indicatively, Lim, 1997; Oh, 2005; Halicioglou, 2010; Smeral, 2012; Eugenio-Martin \& CamposSoria, 2014; Seetaram, Forsyth, \& Dwyer, 2016).

By contrast, there is little empirical work on how variables that move beyond the macroeconomic sphere, such as people's mood and sentiment, might impact on their propensity to consume tourism products (Yap \& Allen, 2011). The role of mood and sentiment in individuals' spending behavior has been widely examined in the economics and psychology literature (Nofsinger, 2005; Weber \& Johnson, 2009) and is acknowledged as an important determinant of many economic aspects, ranging from consumer expenditure (Carroll, Fuhrer, \& Wilcox, 1994; Ludvigson, 2004) to stock market returns (Baker \& Wurgler, 2006). 
Tourism studies offer some evidence that consumer sentiment and mood relate to national tourism demand (Yap \& Allen, 2011) and the way tourists evaluate hospitality services (Sirakaya, Petrick, \& Choi, 2004). Motivated by this line of research, this paper investigates the spillover effects of shocks to mood and sentiment on US outbound tourism to all destinations. The US is one of the largest suppliers of tourists worldwide (UNWTO, 2014) and thus a key market for many destination countries.

To approach this market through the emotional dimension, we use the Index of Consumer Sentiment (ICS) and the Economic Policy Uncertainty (EPU) index, as two proxies for sentiment and the S\&P500 index, as a proxy for mood. The ICS can capture sentiment in relation to consumers' expectations about their own financial condition and the future of the economy, whereas the EPU index can grasp sentiment in relation to the macroeconomic environment of the country. Moreover, as expressed by Nofsinger (2005) and Olson (2006), stock market indices, such as the S\&P500, have the ability to reflect social mood.

This paper is timely in view of the recent Global Financial Crisis (GFC) of 2007-09, which had a major impact on consumer sentiment and economic policy uncertainty in the US. Furthermore, the GFC saw the collapse in stock prices associated with an unprecedented increase in investor fear as measured by the CBOE VIX index. The VIX being an implied volatility index, based on S\&P500 options, expresses expected future market volatility over the next 30 calendar days. This climate could have possibly created spillover effects on consumers' mood and their spending behavior, especially towards luxury goods, such as tourism. The tourism literature has already started to investigate market interdependences in outbound tourism from one origin country to multiple source markets, an area of research that is developing in response to the recent crisis (Song et al., 2012).

The contribution of this paper can be described succinctly. Unlike previous studies (e.g. Yap \& Allen, 2011), we investigate the spillover effects of shocks to consumer sentiment, mood and outbound tourism demand using three different proxies. With the exception of the ICS, the other two proxies are used in 
the tourism literature for the first time. Additionally, the manner of the ICS inclusion represents a significant departure from the literature. Instead of employing the ICS as a determinant of either tourism demand at a national level (Crotts, Thunberg \& Shifflet, 1993; Yap \& Allen, 2011) or international tourism arrivals in destination countries (Gounopoulos, Petmezas, \& Santamaria, 2012), we use it as a sentiment proxy to investigate its spillover effects on the aggregate US outbound tourism demand.

Finally, this study contributes to the existing literature of tourism demand determinants by outlining the importance of shocks to sentiment and mood on the forecast-error variance in outbound tourism demand. So far, tourism studies have examined travelers' sentiment and mood, mainly through the use of qualitative surveys but have overlooked these determinants at macro level. Thus, using historical data on sentiment and mood at macro level opens up a new avenue of research by identifying the spillover effects on tourism demand as a result of shocks originating from the US.

Our findings provide evidence of significant spillover effects among sentiment, mood and outbound tourism demand, which range from $25 \%$ to $55 \%$, indicating moderate to strong interdependencies among the variables. Important peaks are observed during the early-2000 recession, the period 2005-2006 and the GFC, in which shocks to all sentiment and mood indicators are mainly transmitters of spillover effects to the US outbound tourism demand. The only exception is the period 2001-2003 when tourism demand transmitted shocks to mood, which can be attributed to the after-effects of the 9/11 terrorist attacks. Additionally, sentiment and mood indicators reveal heterogeneous patterns in their magnitude of effects across time. In particular, the ICS transmits spillover effects to tourism demand during the early-2000 recession, yet its effects gradually decrease. In contrast, shocks to EPU transmit significant spillover effects in the pre- and latter months of the GFC. Further, the S\&P500 is the main transmitter of shocks during 2005-2006 and in the first year of the GFC.

This paper bears important implications for policymakers in terms of planning and investment, particularly for countries which are popular destinations among the US nationals: Mexico, Canada, the 
UK, Dominican Republic and France (US National Travel and Tourism Office, 2013). As our study suggests, mood and sentiment should be factored into forecasting models for national tourism planning. For instance, when the US sentiment and mood is high, policymakers in key destination countries could strengthen their marketing campaigns in order to attract more US tourists, whereas when US sentiment and mood are low, they could focus their marketing strategies on alternative source countries.

\section{LITERATURE REVIEW AND HYPOTHESIS DEVELOPMENT}

\section{Determinants of Tourism Demand}

The main drivers of outbound tourism demand of sentiment (both consumer and policy uncertainty) and mood can be construed as leading signals of economic conditions in the source market. The importance of leading signals of economic conditions within the economics literature is that they can be used to forecast turning points in the business and economic cycle. The identification of factors influencing tourism consumption is of central concern to researchers and policymakers. There have been a number of variables identified in the literature as determinants of tourism demand.

One of the most widely used explanatory variables is income in origin countries. To account for this, researchers often use the gross domestic product or gross national product per capita (Halicioglou, 2010). These two variables serve as proxies for discretionary income (Song, Witt \& Fei, 2010), given that tourism is generally acknowledged as a luxury good (Kim, Park, Lee \& Jan, 2012). Another determinant of demand is the relative price of tourism. The latter is expressed by dividing the consumer price indices of the destination and the origin country (Gounopoulos et al., 2012), often with exchange rate adjustments (Song et al., 2010). Other variables that can potentially determine tourism demand are prices

of alternative destinations (Song \& Witt, 2003), unemployment (Cho, 2001) or transportation costs (Turner \& Witt, 2001).

The fact that economic factors dominate the tourism demand literature could be partially attributed to 
data availability for economic compared to non-economic factors. Yet recently published work has rendered important the study of non-economic variables as determinants of tourism demand. For instance, Goh, Law and Mak (2008) examine the US and UK tourism demand for Hong Kong, using economic and non-economic factors. Their findings indicate that climate and leisure time, have a greater impact on tourism arrivals than economic factors. Moreover, Cazanova, Ward and Holland (2014) explore economic and non-economic drivers of tourism demand and demonstrate that the latter, as approximated by weather, wildfires and the 9/11 events, exert significant influences. Other noneconomic proxies employed in the literature include habits, similar preferences and climate between inbound and outbound markets (Lorde, Li \& Airey, 2015); advertising (Divisekera \& Kulendran, 2006; Kronenberg, Fuchs, Salman Lexhagen \& Höpken, 2015); immigration (Seetaram \& Dwyer, 2009); political instability (Dhariwal, 2005) or terrorist attacks (Bonham, Edmonds, \& Mak, 2006; Arana \& León, 2008).

\section{Sentiment and Mood}

Even though "sentiment" and "mood" are often used interchangeably, both concepts have distinct differences in terms of their duration and driving forces (for an excellent review of the differences among emotions, mood and sentiment, see Ekman \& Davidson, 1994). In general, one could characterize mood as an emotionally motivated, pre-rational force of the human psyche spanning over short horizons. For example, a person could feel happy or sad for as little as one hour to several days. In addition, mood does not require any cognitive involvement as it is emotionally driven. Frijda (1994) suggests that mood could be unintentional or generated by emotionally charged events (natural disasters, wars, etc.). Furthermore, external factors such as the environment can affect mood. In an earlier paper, Schwartz and Clore (1983) suggested that rainy and cloudy days can induce a depressing mood, while sunny days can produce a positive mood. In the cases of such commonly 
observed stimuli (major events; weather) mood is affected at the collective level (social mood). Conversely, sentiment represents a cognitively motivated, rationalized expression of social disposition. Sentiment tends to last for relatively longer periods and does not change instantaneously. According to Frijda (1986), sentiment is the attitude towards particular events or situations following cognitive involvement. Frijda (1994) later adds that sentiments are cognitive schemas (e.g. expectations) whose informational content determines our perception of things. For example, when individuals are invited to surveys to express their opinion about the economy, the degree to which they feel optimistic or pessimistic requires them to involve their cognitive skills. In other words, they need to recall information from their memory and process it in order to answer the survey questions.

\section{Consumer Sentiment and Tourism Demand}

Consumer sentiment refers to people's feelings about their own finances, the state of the economy and their confidence about its future prospects. Sentiment is believed to exhibit a positive correlation between consumption behavior and spending decisions (Bryant \& Macri, 2005). In particular, consumers' expectations about their personal financial condition and the future of the economy are usually reflected upon survey measures such as the Michigan's Index of Consumer Sentiment (ICS) and the Conference Board's Consumer Confidence Index.

For instance, the ICS is designed to gauge consumer attitudes toward the overall business climate, the state of personal finances, and consumer spending by asking questions to at least 500 households, every month, on the following topics: i) personal financial situation now and a year ago; ii) personal financial situation one year from now; iii) overall financial condition of the business for the next twelve months; iv) overall financial condition of the business for the next five years and; v) current attitude toward buying major household items. From the responses generated, the index provides readings on how consumers view their own financial situation, the short-term general economy and long-term general 
economy to approximate consumer sentiment.

Similarly, the Conference Board's Consumer Confidence Index seeks to identify the level of optimism in the state of the economy, surveying 5,000 households on five issues, namely; (i) current business conditions; (ii) business conditions for the next six months; (iii) current employment conditions; (iv) employment conditions for the next six months and; (iv) total family income for the next six months. Baker, Bloom and Davis (2013) suggest that the Conference Board Confidence index has a correlation of 0.912 with the ICS, thus we only consider the former.

ICS and consumer confidence indicators have been found to be an important non-economic driver of tourism demand. For instance, Crotts et al. (1993) use the ICS as a determinant of domestic US travel, suggesting that it could be a valid proxy for leisure travel. Indeed, they find this index to be an effective short-term predictor for the US domestic travel volume. Later studies report similar findings when using household debt as a proxy for consumer confidence in relation to Australian domestic tourism demand (Athanasopoulos \& Hyndman, 2008; Yap \& Allen, 2011).

Furthermore, Singal (2012) posits that the US consumer sentiment is an important determinant of expenditure in the domestic hospitality industry. Yet, Gounopoulos et al. (2012) do not identify any effect from the consumer confidence index of six origin countries to inbound tourism in Greece. This could be attributable to the fact that they consider people travelling to a single destination and not total outbound tourism from key origin countries. Additionally, these results may differ from the previous literature as they focus on international rather than domestic tourism demand.

The theoretical justification behind the use of ICS as a potential source of spillover from a shock to consumer sentiment on outbound tourism demand originates from the early studies of Katona (1975; 1980). Both studies postulate that increases in consumer sentiment due to increased optimism on future economic prospects translate into increased expenditure and consumption of luxury goods such as tourism. This is based on the assertion that the level of expenditure on non-essential goods is not only 
an indication of one's purchasing power but also a reflection of one's willingness to purchase and consume. As a result, expectations of future income and wealth are regarded as important factors that affect consumers' behavior on whether or not to spend on luxury goods and services. In fact, a number of studies have found that consumer sentiment indexes have forecasting power on consumer spending patterns (Carroll et al., 1994; Ludvigson, 2004; Easaw, Garratt, \& Heravi, 2005).

Based on the above, it follows that expectations about the future of the economy, as reflected in survey measures, can be used to explain tourism demand behavior. Such a proposition is consistent with the findings of Kim et al. (2012) in relation to outbound tourism in Korea. Thus, we posit the first testable hypothesis:

H1. A shock to the ICS transmits spillover effects to the US outbound tourism demand.

Hence, acceptance of hypothesis H1 is consistent with the notion that tourism is highly cyclical and dependent on the economic cycle (Guizzardi \& Mazzocchi, 2010). Based on the assumption used in previous studies that household debt is used to proxy for consumer confidence (Crouch et al. 2007) it follows that a shock to the ICS will have a spillover effect on outbound tourism demand. The intuition here is that when faced with high debt levels, households postpone discretionary expenditure to make debt repayments.

\section{Economic Policy Uncertainty and Tourism Demand}

A novel contribution of this study is the inclusion of the Economic Policy Uncertainty (EPU) index as an alternative measure of sentiment and source of spillover effects to the US outbound tourism demand. Introduced by Baker, Bloom and Davies (2012), the EPU index is constructed by using three components. The first component reflects the media coverage of economic policy uncertainty news; the 
second component considers the federal tax code provisions to expire whereas the third component uses economic analysts' disagreement on their forecasts about policy related variables. By construction all three components of EPU capture concerns about the future state of the economy, thus reflecting changes in economic confidence (Baker et al., 2013). Given that confidence indices (such as the ICS) can capture sentiment, as already mentioned, we maintain that EPU is also a valid proxy for sentiment.

EPU could directly affect consumer spending behavior, as suggested by Giavazzi and McMahon (2012) and Baker et al. (2013). More specifically, Giavazzi and McMahon (2012) find that German households increase their savings (i.e. reduce spending) when policy uncertainty increases. Baker et al. (2013) corroborate the findings by Giavazzi and McMahon (2012), suggesting that increases in economic policy uncertainty makes businesses and households postpone investment, as well as, consumption expenditure.

The EPU index has recently gained traction in the economics literature demonstrating its robustness in measuring policy uncertainty at fiscal and monetary policy level (Antonakakis, Chatziantoniou \& Filis, 2013; Colombo, 2013). Political uncertainty may affect people's welfare in respect to their decisions on saving and consumption (Eeckhoudt, Gollier \& Treich, 2005); as such, one would expect that people would be reluctant to spend for holidays abroad, and vice versa.

The notion that a shock to the EPU index has a transmitting effect on outbound tourism demand is based on Bloom (2009) who investigates the role of economic policy uncertainty on macroeconomic performance. Key to this assertion is the "drop-rebound-overshoot" effect, which predicts that a shock may lead potential travelers to postpone their purchases in the short run, when levels of uncertainty surrounding future income and wealth prospects are high. However, this phenomenon assumes that over time the level of uncertainty diminishes and leads to an increase in demand for non-essential goods and ultimately an overshoot in discretionary spending. This leads us to propose our second hypothesis: 
H2. A shock to the EPU index transmits spillover effects to the US outbound tourism demand.

Acceptance of hypothesis $\mathrm{H} 2$ under the "drop-rebound-overshoot" effect predicts a temporary negative spillover effect in outbound tourism demand followed by a positive effect. An equally plausible explanation is provided by Knotek and Khan (2011), who posit that uncertainty surrounding economic policy would make travelers postpone purchases of luxury goods, particularly goods where there is a cost of cancelling (e.g. airline tickets). As a consequence, a shock would have a negative but temporary spillover effect on outbound tourism demand.

\section{Mood and Tourism Demand}

Similar to sentiment, mood within the context of this study - which refers to the emotional state of individuals - is also believed to have an effect on their expenditure patterns (Gardner, 1985). More specifically, evidence from the psychology literature suggests that mood affects the way we process information and make our decisions under uncertainty even when the source of the mood is not related to the decision being made (Lowenstein et al., 2001). In particular, people in positive (negative) moods have been found to make more optimistic (pessimistic) decisions (Schwarz \& Clore, 1983). It has been observed that when mood is positive, spending is increased and vice versa (Murray et al., 2010). Further, consumption patterns may be heavily disturbed by exceptional events that tend to affect household mood (Malgarini \& Margani, 2007).

A number of studies investigate the effect of mood and emotions on tourism demand using qualitative research methods. Gnoth et al. (2000) conduct a survey in Austria, New Zealand and South Africa to find that emotions and mood have an impact on the motivations of people to travel. In addition, Sirakaya et al. (2004) examine the role of mood in the evaluation of tourism products by cruise passengers, observing that people in bad mood had lower levels of satisfaction. Bigne and Andreu (2004) outline 
the role of emotions in tourist segmentation to report that tourists in Spain who visited cultural attractions exhibited higher levels of satisfaction, loyalty and willingness to spend. Chuang (2007) finds that people in a state of positive emotion are less likely to respond to a sale promotion and opt for a full packaged tour. Finally, Kwortnik and Ross (2007) highlight the importance of consumers' emotions when they take decisions on experiential products, such as vacations.

However, unlike previous studies, we propose the S\&P500 index as a proxy for the level of mood of potential travelers. Its inclusion as a driver of tourism demand, whilst marking another contribution to the tourism literature, stems from psychological evidence and Prechter's (1999) socioeconomic theory. Several researchers have suggested that the stock market could actually reflect the prevailing social mood. For instance, Prechter's (1999) socioeconomic theory suggests that mood at a collective level (social mood) is the primary causal variable in stock markets. Nofsinger (2005) suggests that social mood affects the decisions of consumers, investors and corporate managers. To that end, a positive (negative) mood causes decisions biased by optimism (pessimism) and this impacts on consumer behavior (higher or lower expenditure), business and investment activity. Furthermore, Olson (2006) notes that financial trends are heavily influenced by social mood and that the feelings of financial decision makers mirror the overall mood of society. Finally, due to the fact that stock market decisions are made very quickly, the stock market itself reflects social mood rather than sentiment.

Based on the aforementioned arguments, we maintain that a bullish stock market represents positive mood, whereas a bearish stock market indicates a negative mood (Hong \& Stein, 1999). As a consequence, this leads us to our third testable hypothesis:

H3. A shock to the S\&P500 index returns transmits spillover effects to the US outbound tourism demand.

The use of the S\&P500 index in hypothesis H3 is traced back to an emerging strand in the finance 
literature that posits the use of the implied volatility index (VIX) as an important proxy for investors' fear (Petmezas \& Santamaria, 2014). For instance, the VIX index draws useful inferences on options traders' perceptions of risk of the S\&P500 index and how it translates into falls in stock index prices. This notion is reinforced by the psychology literature where individuals' current mood determines their judgment of future events and their reactions towards these events (Wright \& Bower, 1992). Hence, according to the findings of Nofsinger (2005), the spillover effects of mood on tourism demand are attributable to an increase (decline) in the S\&P500 index that translates into an increase (decline) in social mood.

\section{Relationship between Consumer Sentiment, Policy Uncertainty and Mood}

Another issue that would be interesting to consider is the existence of a relationship among the three drivers of tourism demand. A relationship between sentiment and stock prices has been observed in the studies of Otoo (1999) and Jansen and Nahuis (2003), where rising stock prices cause increases in consumer sentiment and vice versa. On the other hand, Fisher and Statman (2003) observe that high consumer sentiment is associated with low stock returns.

Theoretically, there are two channels that could explain the positive relationship between consumer sentiment and asset returns. The first is the wealth effect where higher stock prices translate into greater wealth and optimism (Poterba, 2000). Secondly, stock prices provide a useful leading indicator on future economic conditions, which in turn may determine consumer behavior as households formulate their future income and wealth expectations (Otoo, 1999).

Additionally, one should account for the possibility of a relationship between economic policy uncertainty and the stock prices. This stems from the theoretical framework of Pastor and Veronesi (2012) who establish a relationship between the economic cycle, economic policy uncertainty and stock prices. The link between policy uncertainty and mood has been empirically proven by previous studies 
(Gregory \& Rangel, 2012; Brogaard \& Detzel, 2015). Therefore, the relationship between shocks to consumer sentiment, economic policy uncertainty and the S\&P500 Index (i.e. mood) are accounted for when interpreting evidence of spillover effects on the US outbound tourism demand.

\section{DATA AND METHODOLOGY}

\section{Data}

We use monthly data on ICS and the EPU indices as proxies for sentiment and the S\&P500 index as a proxy for mood. Our proxy for the outbound tourism demand (OUTBOUND) is the outbound tourist departures from the US. The US has been traditionally the largest tourist generating country and remains the largest origin country in terms of tourists' expenditure (World Bank, 2016).

The sample period for these variables is January 1996 until December 2013. The data on the US outbound tourist departures were obtained from the US National Travel and Tourism Office, the data on the EPU index were obtained from the website of Economic Policy Uncertainty (www.policyuncertainty.com), whereas data on the ICS and S\&P500 index are obtained from Datastream ${ }^{\circledR}$. The outbound series is seasonally adjusted. All data were transformed into their first logdifference and are stationary, based on the ADF-test (results are available upon request).

\section{[TABLE 1 HERE]}

Table 1 presents the descriptive statistics of the series. We observe that the EPU is very volatile compared to other indicators, while outbound tourism demand is also fairly volatile. The mean values suggest that the ICS is, on average, declining during the sample period, whereas the opposite holds for the remaining variables. Both the decline of the ICS and the positive value for the EPU indicate that sentiment is worsening throughout the sample period. Contrary to the two sentiment indicators, the S\&P500 and OUTBOUND have positive mean values, implying an improvement in these series during the sample period. The Jarque-Bera test reveals that none of the series is normally distributed and exhibit 
a platykurtic distribution. The ICS and S\&P500 log-returns are negatively skewed, whereas a positive skewness is observed for the EPU and OUTBOUND.

Figure 1 exhibits the evolution of the series during the study period, where several regularities are observed.

\section{[FIGURE 1 HERE]}

First, the ICS shows a declining trend until 2009, which reaches a trough during the GCF and 2011 when the US economy slowed down sharply. The impact of the GFC is also reflected on both the EPU and S\&P500, where a significant increase and decline, respectively, are evident. Regarding outbound tourism demand, we observe a sharp decline during the last quarter of 2001, which can be attributed to the 9/11 terrorist attacks that had a major impact on the U.S. tourism industry. Finally, another decline in the outbound tourism demand is observed during 2010-2011, which again coincides with the slowdown of the US economy.

\section{Spillover Index}

In this study we use the spillover index by Diebold \& Yilmaz (2012), which is the generalized version of the original index by Diebold \& Yilmaz (2009). Spillovers allow for the assessment of the interlinkages between the variables under examination. The spillover index is based on the Vector Auto Regressive (VAR) model developed by Sims (1980) and the notion of variance decompositions. The

Diebold \& Yilmaz (2012) approach uses a generalized VAR framework (Pesaran \& Shin, 1998), where forecast-error variance decompositions are not influenced by the ordering of the variables. The use of such a framework is of particular importance for our study, as there are no prior theoretical arguments for the "correct" ordering of our variables.

The Diebold \& Yilmaz (2012) approach is useful in identifying total, directional, and net spillovers. The total spillovers represent the average contribution of spillovers of shocks across variables 
to the total forecast error variance. Put it simply, total spillovers measure the average level of interdependence among the variables under examination. The directional spillovers decompose total spillovers into those originating from (or going to) a particular source. Finally, net spillovers allow the identification of the main sources of spillover effects by classifying variables as net transmitters or net receivers of shocks.

Given that our aim is to identify the impact of sentiment and mood indicators' shocks on US outbound tourist departures, we concentrate on net pairwise spillover effects. While net spillovers can identify whether US outbound tourist departures are net receivers or transmitters of spillover shocks to all other variables, net pairwise spillovers identify net spillover effects between each sentiment and mood indicator versus US outbound tourist departures.

Hence, based on Diebold \& Yilmaz (2012), a q-order VAR model is estimated, as follows:

$$
\mathbf{y}_{t}=\sum_{i=1}^{q} \mathbf{B}_{i} \mathbf{y}_{t-i}+\varepsilon_{t},
$$

where, $\mathbf{y}_{t}$ is an $\mathrm{N} \times 1$ vector of endogenous variables, $\mathbf{B}_{i}$ are $\mathrm{N} \times \mathrm{N}$ parameter matrices and $\varepsilon_{t}$ is a $\mathrm{N} \times 1$ vector of disturbance terms that are i.i.d. Our VAR model has four variables, namely, the ICS, EPU, S\&P500 and OUTBOUND. The moving average representation of the VAR model in equation (1), which is key to the dynamics of the system, is given by $\mathbf{y}_{t}=\sum_{j=1}^{\infty} \mathbf{A}_{j} \varepsilon_{t-j}$, where the $\mathrm{N} \times \mathrm{N}$ are coefficient matrices $\mathbf{A}_{j}$, which are recursively defined as $\mathbf{A}_{j}=B_{1} \mathbf{A}_{j-1}+B_{2} \mathbf{A}_{j-2}+\ldots+B_{p} \mathbf{A}_{j-p}$, with $\mathbf{A}_{0}$ being the $\mathrm{N} \times \mathrm{N}$ identity matrix and $\mathbf{A}_{j}=0$, for $j<0$. The total, directional, net and net pairwise spillovers are estimated using generalized forecasterror variance decompositions of the moving average representation of the VAR model in Equation (1). Based on Pesaran and Shin (1998), we define the $H$-step-ahead generalized forecast-error 
variance decomposition as follows:

$$
\theta_{i j}(H)=\frac{\sigma_{j j}^{-1} \sum_{h=0}^{H-1}\left(e_{i}^{\prime} \mathbf{A}_{\mathrm{h}} \Sigma e_{j}\right)^{2}}{\sum_{h=0}^{H-1}\left(e_{i}^{\prime} \mathbf{A}_{\mathrm{h}} \Sigma \mathbf{A}_{h}^{\prime} e_{i}\right)}
$$

where $\sum$ denotes the variance matrix of the error vector $\varepsilon, \sigma_{j j}$ denotes the error term's standard deviation for the $j$-th equation and $e_{i}$ is a selection vector with ones as the $i$-th element and zeros otherwise. This provides a $\mathrm{N} \times \mathrm{N}$ matrix $\theta(H)=\left[\theta_{i j}(H)\right]_{i, j=1,2}$, where each entry gives the contribution of variable $j$ to the forecast error variance of variable $i$. The own-variable contributions are depicted in the main diagonal, whereas off-diagonal elements generate cross-variable contributions.

Under the generalized decomposition, the sum of own and cross-variable variance contribution is not equal to one, i.e. $\sum_{j=1}^{N} \theta_{i j}(H) \neq 1$. Thus, all entries of the variance decomposition matrix are normalized by the row sum, as follows:

$$
\tilde{\theta}_{i j}(H)=\frac{\theta_{i j}(H)}{\sum_{j=1}^{N} \theta_{i j}(H)}
$$

We should note here that by construction $\sum_{j=1}^{N} \tilde{\theta}_{i j}(H)=1$ and $\sum_{i, j=1}^{N} \tilde{\theta}_{i j}(H)=N$.

Based on equations (2) and (3), we can estimate the total spillover index (TS), as follows:

$$
T S(H)=\frac{\sum_{i, j=1, i \neq j}^{N} \tilde{\theta}_{i j}(H)}{\sum_{i, j=1}^{N} \tilde{\theta}_{i j}(H)} \times 100=\frac{\sum_{i, j=1, i \neq j}^{N} \tilde{\theta}_{i j}(H)}{N} \times 100 .
$$


Furthermore, the directional spillovers TO variable $i$ FROM all other variables $j$, are computed as follows:

$$
D S_{i \leftarrow j}(H)=\frac{\sum_{j=1, i \neq j}^{N} \tilde{\theta}_{i j}(H)}{\sum_{i, j=1}^{N} \tilde{\theta}_{i j}(H)} \times 100=\frac{\sum_{j=1, i \neq j}^{N} \tilde{\theta}_{i j}(H)}{N} \times 100
$$

whereas, the directional spillovers FROM variable $i$ TO all other variables $j$ is estimated as follows:

$$
D S_{i \rightarrow j}(H)=\frac{\sum_{j=1, i \neq j}^{N} \tilde{\theta}_{j i}(H)}{\sum_{i, j=1}^{N} \tilde{\theta}_{j i}(H)} \times 100=\frac{\sum_{j=1, i \neq j}^{N} \tilde{\theta}_{j i}(H)}{N} \times 100
$$

In turn, equations (5) and (6) enable us to estimate the net spillovers (NS) from variable $i$ to all other variables $j$, as:

$$
N S_{i}(H)=D S_{i \rightarrow j}-D S_{i \leftarrow j}
$$

Finally, the net pairwise spillovers can be calculated as:

$$
N P W S_{i j}(H)=\left(\frac{\tilde{\theta}_{j i}(H)-\tilde{\theta}_{i j}(H)}{N}\right) \times 100 .
$$

\section{EMPIRICAL RESULTS}

The spillover results for the full sample estimation are shown in Table 2. Our findings indicate that, on average, the total spillover index is $20.4 \%$, which suggests a moderate interdependence among the four variables. The net spillovers reveal that only the EPU is a net transmitter of shocks to all other variables $(17.4 \%)$, whereas the remaining three variables are all net receivers of shocks. Furthermore, outbound tourism does not seem to be heavily impacted by any of the other 
three indicators, given that on the full sample estimation the own contributions of shocks to its own forecast error variance is $99.7 \%$.

\section{[TABLE 2 HERE]}

However, a static approach may mask some important interdependencies that can only be revealed in a time-varying framework. This is a valid argument, given that the interdependencies among our variables could have been affected by major events during the sample period, which could alter the households' sentiment and social mood. These may include the 9/11 terrorist attacks, the Iraqi war and the GFC. Thus, it is important to assess how these spillover effects change over time.

To do so, we generate the spillover effects of shocks using a 60-month rolling window estimation of equation (1) with 12-months step-ahead generalized forecast-error variance decomposition. For robustness, we also considered alternative window lengths (72-month and 84-months) and different periods for the generalized forecast-error variance decomposition (6 and 24 months) and the results remain qualitatively similar. For brevity, robustness tests results are only available upon request. The results of the time-varying total spillover effects are shown in Figure 2.

\section{[FIGURE 2 HERE]}

Although on the static approach the total spillover index is $20.4 \%$, when we consider a timevarying approach, the results are different and more informative. First, we notice that the total spillover index fluctuates between $25 \%$ and 55\%, while a continuous decline is observed. Furthermore, four peaks are observed in the total spillover index; the first during the 2000-2001 period, the second during the period 2005- 2006, the third during the 2007-2009 GFC and the forth during the latter part of 2013.

The US outbound tourism demand is particularly sensitive to shocks introduced to all sentiment and mood proxies as highlighted by the highest reading of almost $55 \%$ in $2000-2001$. This could be attributable to the US recession during this period and more crucially, the detrimental effects of the 
9/11 on the air-travel industry. This is a very interesting finding, given that safety issues and the sense of social security are more commonly relevant to destinations (Bonham et al., 2006). However, in this case the terrorist attacks seem to act as a reverse push factor, given that a perceived risk to travel, prevalent in the origin country, discourages people's mobility (Ito \& Lee, 2005).

We observe spillover effects to be of lower magnitude during the GFC, which although unexpected, can be explained by the fact that interdependencies among mood, sentiment and outbound tourism are gradually shrinking over time. Thus, upon closer inspection, we realize that during the peak of the GFC (towards the end of 2008) spillover effects increase from about $30 \%$ to approximately $45 \%$ (i.e. a $50 \%$ increase in spillovers). The corresponding increase in the early-2000 recession is about $22 \%$. This suggests that all four variables in our model become highly interrelated during recessionary periods. Such findings support and extend the existing literature, which has showed that there are strong relationships among different sets of these variables (Jansen \& Nahuis, 2003; Pastor \& Varonesi, 2012).

Turning to non-recessionary periods, we observe a peak in 2005-2006, which coincides with the most active Atlantic hurricane season in US history that caused thousands of casualties and billiondollar damages. Plausibly, this peak could be driven by changes in social mood, on the premise that the latter is affected by natural disasters, as established by Frijda (1994). Furthermore, the tourism literature provides evidence of the effect of natural disasters on decreasing inbound tourist flows in destination countries (Sharpley, 2005) and that natural disasters create hesitancy in travelling (Wang, 2009). Here, once again, we observe that a traditional pull factor may also affect outbound tourist flows dramatically.

Furthermore, the hardest-hit areas during this hurricane period were the Gulf Coast and the Gulf of Mexico. This led to a speculative rise in oil prices, as both regions are crucial for the oil industry 
(according to the US FTC (2006), the gasoline price reached a record price). Past research provides evidence that increased oil prices negatively affect tourism demand (Becken \& Lennox, 2012) and economic prospects (Hamilton, 2011). Thus, it makes sense to argue that such events could impact on both sentiment and mood and in turn, affect decisions for engaging in outbound travel.

The last peak in the total spillover index, which is observed in the latter part of 2013, can be attributed to improving ICS readings, declining EPU and the S\&P500 reaching historic highs, closing above the 2000 points for the first time. These conditions could trigger higher outbound tourism demand, given improvements in readings of sentiment and mood.

Overall, total spillovers illuminate that during periods of major events, the spillover effects of shocks amongst our variables increase significantly. Nevertheless, we need to disentangle these shocks and their relationship further. Given that our key interest is to identify how each indicator affects outbound tourism demand, we only concentrate on directional spillovers TO outbound tourism demand and net pairwise spillover effects between each proxy and outbound tourism demand. All remaining time-varying spillover indices (directional and net spillovers) are not reported here but are available upon request.

Figure 3 exhibits the directional spillovers transmitted FROM all three indicators TO outbound tourism demand.

\section{[FIGURE 3 HERE]}

The directional spillover effects fluctuate between $4.5 \%$ and $12 \%$ over the sample period, which suggests moderate impact of sentiment and mood indicators' shocks on outbound tourism demand. Furthermore, four peaks can be observed, which coincide with the periods identified earlier in the total spillover index and as such, these spillover effects confirm that shocks to sentiment and mood can affect outbound tourism demand behavior. More important, though, is to isolate the spillover 
effects from each indicator. This can be achieved by examining the time-varying net pairwise spillover effects, presented in Figure 4.

\section{[FIGURE 4 HERE]}

In general, we observe that shocks to sentiment and mood indicators are net transmitters of spillover shocks to outbound tourism demand. The only exception is the 2001-2003 period when tourism demand transmits shocks to the S\&P500. Furthermore, we notice that the magnitude of these spillover effects differs across sentiment and mood indicators, implying that the impact of shocks on outbound tourism demand is heterogeneous and that the indicator which exercises the greatest impact shifts over time.

Starting with the interdependency between the ICS and outbound tourism demand, it is clear that the spillover effects are almost zero from 2005 onwards. Nevertheless, there is a peak in the early-2000 recession, when spillover effects from an ICS shock on outbound tourism demand reach the level of $10 \%$. Furthermore, we observe a peak of about $4 \%$ in the net transmitting role of shocks to ICS during the latter part of the GFC. Overall, the impact of ICS shocks on outbound tourism demand seems to be negligible, although this does not hold during economic downturns. This contradicts the findings of Athanasopoulos and Hyndman (2008) and Yap and Allen (2011), who maintain that consumer confidence is an important determinant of domestic tourism demand yet it does corroborate with the findings of Gounopoulos et al. (2012).

The net pairwise spillover effects of shocks to EPU and outbound tourism demand provide a different narrative compared to ICS shocks. In particular, EPU shocks have a moderate effect of approximately $4 \%$ on outbound tourism, with the highest reading observed during the pre-GFC period, when the EPU recorded its lowest levels. This demonstrates that when EPU in normal periods is positive, households exhibit a higher demand for outbound tourism. These findings are related to the positive effects that low levels of macroeconomic policy sentiment (i.e. EPU) could 
exercise on outbound tourism (Knotek \& Khan, 2011).

On the other hand, we find that EPU is a net transmitter of spillover effects on outbound tourism demand during the early-2000 recession and the GFC (i.e. when EPU index readings reach significantly high levels). Such a finding is consistent with Bloom (2009) and Knotek and Khan (2011), who suggest that when sentiment is negative, households tend to cut down their demand for holidays abroad.

Finally, a particularly interesting finding lies in the spillovers between S\&P500 and outbound tourism demand, where S\&P500 is a net transmitter of spillover shocks during the whole study period apart from 2001-2003, which coincides with the 9/11 attacks and its aftermath. Indeed, in the years following 9/11, the airline industry experienced a significant reduction in passenger enplanements and revenues (IATA, 2011). According to the IATA (2011) report, it was the first time since the World War II that the capacity of the airline industry declined in two consecutive years.

Turning our attention to the remaining period, we observe that the net transmitting role of the S\&P500 to outbound tourism demand reaches its peak during the GFC. This highlights the role of mood on international travel during a period of severe economic distress and especially within the "cyclone's eye" phase of the crisis. Furthermore, a significant increase in spillover effects is evident during 2005-2006. As mentioned earlier, this period which is characterized by the highest activity of Atlantic hurricanes, not only impacted on the US economy but also created significant speculation in the oil market. As expected, both environmental and oil price shocks tend to exercise a negative impact on households' mood (Frijda, 1994), which in turn can affect their decisions regarding outbound tourism (Becken \& Lennox, 2012). 


\section{FURTHER DISCUSSION OF RESULTS}

Based on our findings, we can accept our testable hypotheses. First, we maintain that the consumer sentiment hypothesis (H1) is marginally accepted as we find significant spillover effects only in the first years of our sample period. According to Crouch et al. (2007), this may be indicative of shocks impacting on the wellbeing of households with high debt levels, which lead to delays in discretionary spending to meet their debt obligations.

Second, the hypothesis related to EPU shocks $(\mathbf{H 2})$ can be accepted given that asymmetric responses from tourism demand are observed. More specifically, when economic uncertainty is high (early2000 recession and the GFC), we report spillover effects from EPU to outbound tourism. In contrast, when EPU is low, we do not observe any important spillover effects. This provides some support for the "drop-rebound-overshoot" effect postulated by Bloom (2009) where uncertainty shocks lead travelers to postpone their travel plans in periods of recession and market turbulence.

Third, the hypothesis concerning the effects of mood on the US outbound tourism demand (H3) should also be accepted. This is because the main shock to the S\&P500 during the GFC transmitted significant spillover effects to tourism demand. Such finding is consistent with Nofsinger (2005), who shows that a decrease in tourism demand is caused by a decline in social mood, especially when investors' fear reaches unprecedented levels, as depicted by declines (increases) in the VIX index (Petmezas \& Santamaria, 2014).

Finally, another noteworthy result of this paper is the differential spillover effects of sentiment and mood to outbound tourism demand that is time varying and diverse in terms of duration. The differential results between spillover effects of the ICS and mood to tourism demand are consistent with the findings of Fisher and Statman (2003) who report an inverse relationship between consumer sentiment and stock returns. On the other hand, establishing a net spillover effect (pre-GFC period) from the EPU index and mood to tourism demand does suggest an empirical relationship between 
economic policy uncertainty and stock market performance (Gregory \& Rangel, 2012). However, given that this finding is not robust across time, there are question marks on the strength of the empirical relationship when aligned to the theoretical link between policy uncertainty and asset returns (Pastor \& Veronesi, 2012).

\section{CONCLUSION}

The identification of factors that motivate or de-motivate individuals to engage in outbound tourism is of major importance for destination countries that aim to attract international visitors and realize tourism opportunities for their socio-economic development. However, a mismatch in the literature is observed between a plethora of studies which examine the macroeconomic influences of tourism demand and the limited work that explores the impact of sentiment and mood on travelling abroad. This study fills this void by examining the effect of sentiment and mood shocks on outbound tourism demand from the US, one of the key tourism-generating markets worldwide.

More specifically, even though tourism demand has been widely investigated through purely economic lenses, the desire to travel is also underpinned by socio-psychological parameters, which affect consumer behavior. Our analysis considers this socio-psychological dimension, showing that mood and sentiment, viewed as internal aspects of origin markets, can also be used to explain tourism demand.

The paper adopts the Diebold \& Yilmaz (2012) spillover index approach and employs two indices that correspond to sentiment. Sentiment is defined as consumer's expectations about their own financial condition and the future of the economy (as expressed by the ICS) and uncertainty towards macroeconomic policy (as expressed by the EPU index). We also use a proxy that reflects social mood, which is the S\&P500 stock market index. The use of these proxies for exploring the said relationship is introduced here for the first time in tourism studies. 
In brief, the study provides evidence that there are spillover effects of shocks to sentiment and mood on outbound tourism demand, although not of high magnitude at all times. Thus, it should be noted that the impact of sentiment and mood on tourism demand is time and event dependent. In essence, we observe that spillover effects vary dramatically during periods of political, environmental and economic shocks, such as the 9/11 attacks, the 2005-2006 hurricanes, and the GFC. Although such findings are perhaps not surprising, it establishes that tourism demand is not just susceptible but rather tightly integrated in a dynamic web of events, played in the origin countries.

The new evidence on the effect of mood and sentiment on tourism demand gives rise to important policy implications. In particular, it is suggested that destinations which attract significant numbers of US tourists (e.g. Mexico, Canada, the UK, Dominican Republic and France) need to consider not only the economic measurements of tourism demand but also their corresponding emotional determinants when devising tourism growth strategies and policy measures. Our findings demonstrate that emotional factors need to be considered in the tourism planning of these destinations, particularly in the event of shocks originating in source markets. The use of a combination of economic and emotional determinants of tourism demand in forecasting models can enhance both predictive capacity and forecasting accuracy, which can, in turn, inform destinations' reactions to tourist arrivals fluctuations. Further, measurements of people's sentiment and mood, as receivers and reflectors of local phenomena, could help tailor promotional tactics of destinations that aim to sustain traditional markets or approach new ones.

This paper makes a step towards explaining how non-macroeconomic factors in origin markets can affect individuals' willingness to travel abroad. It aspires to stimulate further and more indepth research on an interesting and hugely unexplored topic. Future studies could attempt to examine the emotional responses of potential outbound travelers more systematically - by extending this line of enquiry into other key origin markets. A cross-market enquiry could be 
particularly relevant given that some tourism generating regions might be more or less susceptible to sentiment or mood changes. Further, possible extensions of this study could employ other sets of emotional factors and proxies. For instance, recent studies use social media to capture mood and sentiment (Siganos, Vagenas-Nanos \& Verwijmeren, 2014).

Acknowledgements - We thank the editors, Juergen Gnoth and John Tribe, and the three anonymous referees for their valuable comments. The authors would also like to thank Vasileios Kallinterakis for his comments on an earlier version of this paper. This work began during Mina's Dragouni time as a research assistant at Bournemouth University. The authors are solely responsible for any remaining errors and deficiencies. 


\section{REFERENCES}

Antonakakis, N., Chatziantoniou, I., \& Filis, G., (2013). Dynamic co-movements of stock market returns, implied volatility and policy uncertainty. Economics Letters, 120, 87-92.

Arana, J. E., \& León, C. J. (2008). The impact of terrorism on tourism demand. Annals of Tourism Research, 35(2), 299-315.

Athanasopoulos, G., \& Hyndman, R.J., (2008). Modelling and forecasting Australian domestic tourism. Tourism Management, 29(1), 19-31.

Baker, M., \& Wurgler, J. (2006). Investor Sentiment and the Cross-Section of Stock Returns. The Journal of Finance, 61(4), 1645-1680.

Baker, S., Bloom, N., \& Davis, S. (2012). Measuring economic policy uncertainty. Available at: http://www.policyuncertainty.com.

Baker, S., Bloom, N., \& Davis, S. (2013). Measuring economic policy uncertainty. Chicago Booth research paper, (13-02).

Becken, S., \& Lennox, J. (2012). Implications of a long-term increase in oil prices for tourism. Tourism Management, 33(1), 133-142.

Bigne, J.E. \& Andreu, L., 2004. Emotions in segmentation: An empirical study. Annals of Tourism Research, 31(3), 682-696.

Bloom, N. (2009). The impact of uncertainty shocks. Econometrica, 77(3), 623-685.

Bonham, C., Edmonds, C., \& Mak, J. (2006). The impact of 9/11 and other terrible global events on tourism in the United States and Hawaii. Journal of Travel Research, 45(1), 99-110.

Brogaard, J., \& Detzel, A. (2015). The asset-pricing implications of government economic policy uncertainty. Management Science, 61(1), 3-18.

Bryant, A. W. D., \& Macri, J. (2005). Does sentiment explain consumption? Journal of Economics and Finance, 29(1), 97-110. 
Carroll, C. D., Fuhrer, J. C., \& Wilcox, D. W. (1994). Does Consumer Sentiment Forecast Household Spending? If So, Why?, The American Economic Review, 84(5), 1397-1408.

Cazanova, J., Ward, R. W., \& Holland, S. (2014). Habit Persistence in Air Passenger Traffic Destined for Florida. Journal of Travel Research, 53(5), 638-655.

Cho, V. (2001). Tourism forecasting and its relationship with leading economic indicators. Journal of Hospitality \& Tourism Research, 25(4), 399-420.

Chuang, S. C (2007). The effects of emotions on the purchase of tour commodities. Journal of Travel and Tourism Marketing, 22(1), 1-13.

Colombo, V. (2013). Economic policy uncertainty in the US: Does it matter for the Euro area? Economics Letters, 121(1), 39-42.

Crotts, J. C., Thunberg, E. M. \& Shifflet, D. K. (1993). Consumer Confidence as a Leading Indicator of Change in U.S. Travel Volume. Journal of Travel \& Tourism Marketing, 1(2), 53-62.

Crouch, G. I., Oppewal, H., Huybers, T., Dolnicar, S., Louviere, J. J., \& Devinney, T. (2007). Discretionary expenditure and tourism consumption: Insights from a choice experiment. Journal of Travel Research, 45(3), 247-258.

Diebold, F. X., \& Yilmaz, K. (2009). Measuring Financial Asset Return and Volatility Spillovers, with Application to Global Equity Markets. The Economic Journal, 119(534), 158-171.

Diebold, F. X., \& Yilmaz, K. (2012). Better to give than to receive: Predictive directional measurement of volatility spillovers. International Journal of Forecasting, 28(1), 57-66.

Dhariwal, R. (2005). Tourist Arrivals in India: How Important Are Domestic Disorders? Tourism Economics, 11(2), 185-205.

Divisekera, S. \& Kulendran, N. (2006). Economic effects of advertising on tourism demand. Tourism Economics, 12(2), 187-205.

Easaw, J. Z., Garratt, D., \& Heravi, S. M. (2005). Does consumer sentiment accurately forecast UK 
household consumption? Are there any comparisons to be made with the US? Journal of Macroeconomics, 27, 517-532.

Ekman, P. \& Davidson, R.J. (Eds.). (1994). The Nature of Emotion Fundamental Questions. Oxford: Oxford University Press.

Eeckhoudt, L., Gollier, C., \& Treich, N. (2005). Optimal consumption and the timing of the resolution of uncertainty. European Economic Review, 49(3), 761-773.

Eugenio-Martin, J. L., \& Campos-Soria, J. A. (2014). Economic crisis and tourism expenditure cutback decision. Annals of Tourism Research, 44, 53-73.

Federal Trade Commission. (2006). Investigation of gasoline price manipulation and post-Katrina gasoline price increases. Washington, DC, 69, 86-87.

Fisher, K. L., \& Statman, M. (2003). Consumer confidence and stock returns. The Journal of Portfolio Management, 30(1), 115-127.

Frijda, N.H. (1986). The Emotions. Cambridge: Cambridge University Press.

Frijda, N.K. (1994). Varieties of Affect: Emotions and Episodes, Moods, and Sentiments. In P. Ekman, \& R.J. Davidson (Eds.), The Nature of Emotion Fundamental Questions (pp.59-67). Oxford: Oxford University Press.

Gardner, M. P. (1985). Mood states and consumer behavior: a critical review. Journal of Consumer Research, 12(December), 281-300.

Giavazzi, F., \& McMahon, M. (2012). Policy uncertainty and household savings. Review of Economics and Statistics, 94(2), 517-531.

Gnoth, J., Zins, A. H., Lengmueller, R., \& Boshoff, C. (2000). Emotions, mood, flow and motivations to travel. Journal of Travel \& Tourism Marketing, 9(3), 23-34.

Goh, C., Law, R. \& Mok, H.M.K. (2008). Analyzing and Forecasting Tourism Demand: A Rough Sets Approach. Journal of Travel Research, 46, 327-338. 
Gounopoulos, D., Petmezas, D. \& Santamaria, D. (2012). Forecasting Tourist Arrivals in Greece and the Impact of Macroeconomic Shocks from the Countries of Tourists' Origin. Annals of Tourism Research, 39(2), 641-666.

Gregory, K., \& Rangel, J. (2012). The Buzz: Links between policy uncertainty and equity volatility. Goldman Sachs Global Economics, Commodities and Strategy Research Working Paper.

Guizzardi, A., \& Mazzocchi, M. (2010). Tourism demand for Italy and the business cycle. Tourism Management, 31(3), 367-377.

Halicioglu, F. (2010). An econometric analysis of the aggregate outbound tourism demand of Turkey. Tourism Economics, 16(1), 83-97.

Hamilton, J. D. (2011). Nonlinearities and the macroeconomic effects of oil prices. Macroeconomic dynamics, 15(S3), 364-378.

Hong, H., \& Stein, J. (1999). A unified theory of underreaction, momentum trading, and overreaction in asset markets, Journal of Finance, 54, 2143-2184.

IATA, (2011). Impact of the September 112001 on aviation. Retrieved June, 6 2015, from: http://www.iata.org/pressroom/Documents/impact-9-11-aviation.pdf

Ito, H., \& Lee, D. (2005). Assessing the impact of the September 11 terrorist attacks on US airline demand. Journal of Economics and Business, 57(1), 75-95.

Jansen, W., \& Nahuis, N. (2003). The stock market and consumer confidence: European evidence, Economics Letters, 79, 89-98.

Hirshleifer, D. \& Shumway, T. (2003). Good day sunshine: Stock returns and the weather, Journal of Finance, 58(3), 1009-1032.

Kamstra, M.J., Kramer, L.A. \& Levi, M.D. (2003). Winter Blues: A sad stock market cycle. American Economic Review, 93(1), 1257-1263.

Katona, G. (1980). Essays on behavioral economics. University of Michigan, Ann Arbor, Mich. 
Katona, G., (1975). Psychological economics. New York: Elsevier.

Kay, R.W. (1994). Geomagnetic Storms: Association with incidence of depression as measured by hospital admission. British Journal of Psychiatry, 164, 403-409.

Kim, H. B., Park, J. H., Lee, S. K., \& Jang, S. S. (2012). Do expectations of future wealth increase outbound tourism? Evidence from Korea. Tourism Management, 33(5), 1141-1147.

Knotek, E., \& Khan, S. (2011). How do households respond to uncertainty shocks?. Kansas City Federal Reserve Board Economic Review.

Kwortnik, R.J., \& Ross, W.T. (2007). The role of positive emotions in experiential decisions. International Journal of Research in Marketing, 24, 324-335.

Kronenberg, K., Fuchs, M., Salman, K., Lexhagen, M. \& \& Höpken, W. (2015). Economic Effects of Advertising Expenditures - A Swedish Destination Study of International Tourists. Scandinavian Journal of Hospitality \& Tourism Research, Doi:10.1080/15022250.2015.1101013.

Li, S., Blake, A., \& Cooper, C. (2011). Modelling the economic impact of international tourism on the Chinese economy: A CGE analysis of the Beijing 2008 Olympics. Tourism Economics, 17(2): 279-303.

Lim, C. (1997). Review of international tourism demand models. Annals of Tourism Research, 24(4), 835-849.

Lorde, T., Li, G., \& Airey, D. (2015). Modeling Caribbean Tourism Demand An Augmented Gravity Approach. Journal of Travel Research, doi: 10.1177/0047287515592852.

Lowenstein, G.F., Weber, E.U., Hsee, C.K. \& Welch, N. (2001). Risk as Feelings. Psychological Bulletin, 127 (2), 267-286.

Ludvigson, S. C. (2004). Consumer Confidence and Consumer Spending. Journal of Economic Perspectives, 18(2), 29-50. 
Malgarini, M., \& Margani, P. (2007). Psychology, consumer sentiment and household expenditures. Applied Economics, 39(13), 1719-1729.

Morck, R., Shleifer, A., Vishny, R. W., Shapiro, M., \& Poterba, J. M. (1990). The stock market and investment: is the market a sideshow?. Brookings papers on economic Activity, 157-215.

Murray, K. B., Di Muro, F., Finn, A., \& Leszczyc, P. P. (2010). The effect of weather on consumer spending. Journal of Retailing and Consumer Services, 17(6), 512-520.

Nofsinger, J. (2005). Social mood and financial economics. The Journal of Behavioral Finance, $6(3), 144-160$.

Oh, C. O. (2005). The contribution of tourism development to economic growth in the Korean economy. Tourism management, 26(1), 39-44.

Olson, K. R. (2006). A Literature Review of Social Mood. The Journal of Behavioral Finance, 7(4), 193-203.

Otoo, M. W. (1999). Consumer sentiment and the stock market. Finance and Economics Discussion Paper, Federal Reserve Board.

Pastor, L., \& Veronesi, P. (2012). Uncertainty about government policy and stock prices. The Journal of Finance, 67(4), 1219-1264.

Patsouratis, V., Frangouli, Z., \& Anastasopoulos, G. (2005). Competition in tourism among the Mediterranean countries. Applied Economics, 37, 1865-1870.

Pesaran, H.H., \& Shin, Y. (1998). Generalized impulse response analysis in linear multivariate models. Economics Letters, 58(1), 17-29.

Petmezas, D., \& Santamaria, D. (2014). Investor induced contagion during the banking and European sovereign debt crisis of 2007-2012: Wealth effect or portfolio rebalancing?. Journal of International Money and Finance, 49, 401-424.

Poterba, J. M. (2000). Stock Market Wealth and Consumption, Journal of Economic Perspectives, 
$14,99-118$.

Prechter, Jr., R. R. (1999). The Wave Principle of Human Social Behavior and the: New Science of Socionomics. Gainesville, GA: New Classics Library.

Schwarz, N. \& Clore, G.L. (1983). Mood, misattribution, and judgments of well-being: Informative and directive functions of affective states. Journal of Personality and Social Psychology, 45, 513-523.

Seetaram, N., \& Dwyer, L. (2009). Immigration and Tourism Demand in Australia: A panel Data Analysis. Anatolia, 20(1), 212-222.

Seetaram, N., Forsyth, P., \& Dwyer, L. (2016). Measuring price elasticities of demand for outbound tourism using competitiveness indices. Annals of Tourism Research, 56, 65-79.

Sharpley, R. (2005). The tsunami and tourism: A comment. Current Issues in Tourism, 8(4), 344349.

Siganos, A., Vagenas-Nanos, E., \& Verwijmeren, P. (2014). Facebook's daily sentiment and international stock markets. Journal of Economic Behavior \& Organization, 107(B), 730743.

Sims, C. (1980). Macroeconomics and reality. Econometrica, 48, 1-48.

Singal, M. (2012). Effect of consumer sentiment on hospitality expenditures and stock returns. International Journal of Hospitality Management, 31(2), 511-521.

Sirakaya, E., Petrick, J., \& Choi, H. S. (2004). The Role of Mood on Tourism Product Evaluations. Annals of Tourism Research, 31(3), 517-539.

Smeral, E. (2012). International tourism demand and the business cycle. Annals of Tourism Research, 39(1), 379-400.

Song, H., Dwyer, L., Li, G., \& Cao, Z. (2012). Tourism Economics Research: A Review and Assessment. Annals of Tourism Research, 39(3), 1653-1682. 
Song, H., \& Lin, S. (2010). Impacts of the Financial and Economic Crisis on Tourism in Asia. Journal of Travel Research, 49(1), 16-30.

Song, H., \& Witt, S. F. (2003). Tourism forecasting: the general-to-specific approach. Journal of Travel Research, 42(1), 65-74.

Song, H., Li, G., Witt, S. F., \& Fei, B. (2010). Tourism demand modelling and forecasting: how should demand be measured? Tourism Economics, 16(1), 63-81.

Turner, L., \& Witt, S. (2001). Forecasting tourism using univariate and multivariate structural time series models. Tourism Economics, 7(2), 135-147.

Wang, Y. S. (2009). The impact of crisis events and macroeconomic activity on Taiwan's international inbound tourism demand. Tourism Management, 30(1), 75-82.

Weber, E. U., \& Johnson, E. J. (2009). Mindful judgment and decision making. Annual review of psychology, 60, 53-85.

World Bank (2016). US International Tourism Expenditure (current US\$). Available at http://data.worldbank.org/country/united-states.

Wright, F., \& Bower, H. (1992). Mood effects on subjective probability assessment. Organizational Behavior and Human Decision Processes, 52, 276-291.

Yap, G., \& Allen, D. (2011). Investigating other leading indicators influencing Australian domestic tourism demand. Mathematics and Computers in Simulation, 81(7), 1365- 1374.

United Nations World Tourism Organisation (2014). UNWTO Tourism Highlights. 2014 Edition. 


\section{List of Tables}

Table 1: Descriptive statistics of the series under investigation. Sample runs from 1996:01 $-2013: 12$.

\begin{tabular}{|c|c|c|c|c|c|c|c|}
\hline & ICS & EPU & & SP500 & & OUTBOUND & \\
\hline Mean & -0.0005 & 0.0008 & & 0.0050 & & 0.0039 & \\
\hline Maximum & 0.1347 & 0.8025 & & 0.1188 & & 0.5375 & \\
\hline Minimum & -0.1881 & -0.6289 & & -0.2729 & & -0.3211 & \\
\hline Std. Dev. & 0.0456 & 0.1654 & & 0.0477 & & 0.0585 & \\
\hline Skewness & -0.5651 & 0.7009 & & -1.1508 & & 2.6523 & \\
\hline Kurtosis & 5.4451 & 6.4109 & & 7.5598 & & 38.4373 & \\
\hline Jarque-Bera & 65.0052 & $\begin{array}{ll}* * * & 121.8331 \\
\end{array}$ & $* * *$ & 233.7214 & $* * *$ & 11502.0203 & $* * *$ \\
\hline
\end{tabular}

Table 2: Spillover table (in \%): ICS, EPU, S\&P500 and OUTBOUND returns. The sample runs from 1996:01 - 2013:12.

\begin{tabular}{|c|c|c|c|c|c|}
\hline & ICS & EPU & S\&P500 & OUTBOUND & $\begin{array}{l}\text { Contribution } \\
\text { FROM others }\end{array}$ \\
\hline ICS & 75.3 & 9.1 & 11.4 & 4.2 & 24.7 \\
\hline EPU & 7.5 & 81.8 & 9.2 & 1.5 & 18.2 \\
\hline S\&P500 & 4.6 & 24.9 & 68.9 & 1.6 & 31.1 \\
\hline OUTBOUND & 0.4 & 1.6 & 5.6 & 92.4 & 7.6 \\
\hline $\begin{array}{l}\text { Contribution } \\
\text { TO others }\end{array}$ & 12.5 & 35.6 & 26.2 & 7.3 & $\begin{array}{r}\text { Total } \\
\text { Spillover } \\
\text { Index: }\end{array}$ \\
\hline $\begin{array}{l}\text { Contribution } \\
\text { including } \\
\text { own }\end{array}$ & 87.8 & 117.4 & 95.1 & 99.7 & 20.4 \\
\hline Net spillovers & -12.2 & 17.4 & -4.9 & -0.3 & \\
\hline
\end{tabular}




\section{List of Figures}

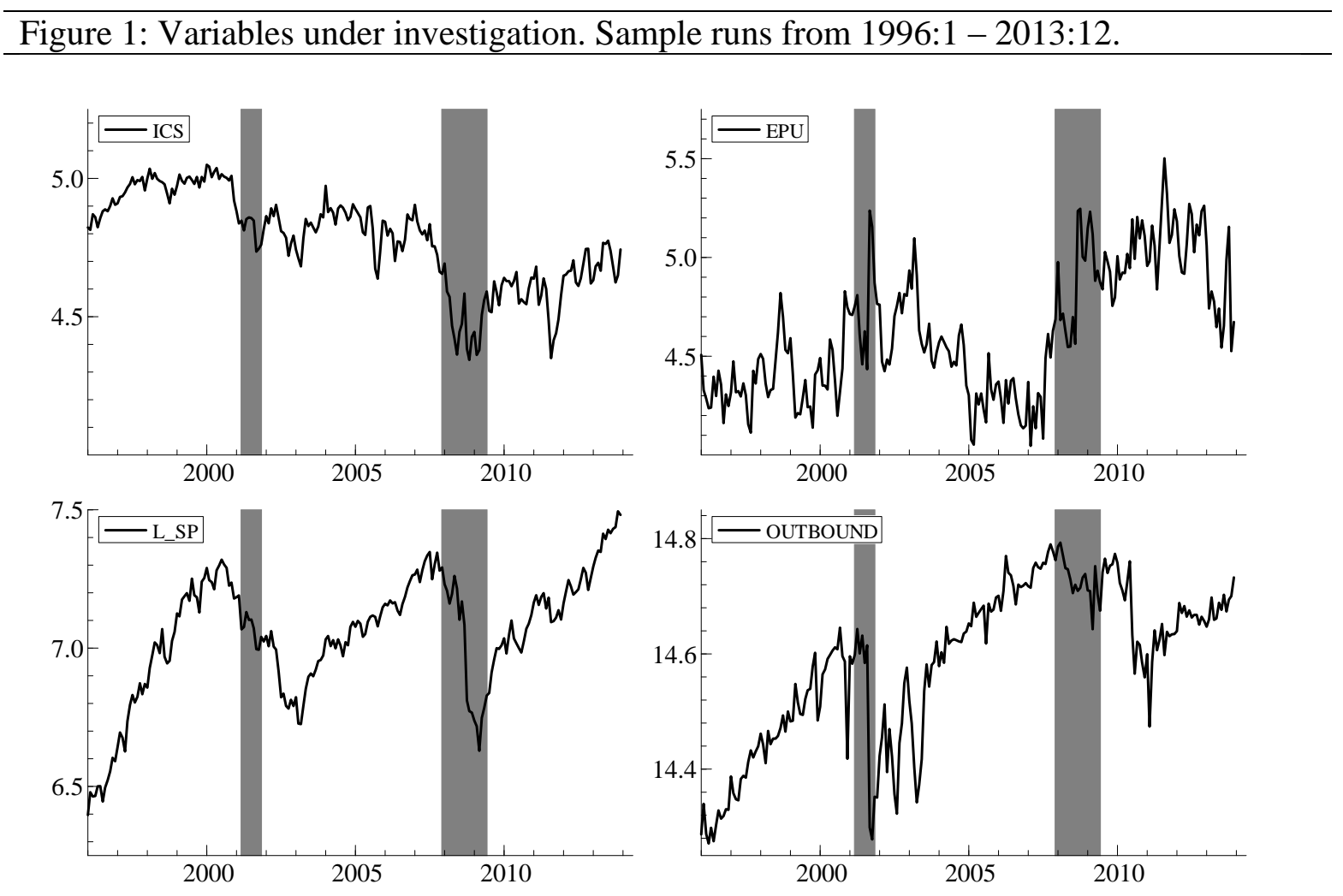

Note: Shading areas denote US recessions as defined by NBER. 
Figure 2: Total spillovers using 60-month rolling window. Sample runs from 1996:1 2013:12.

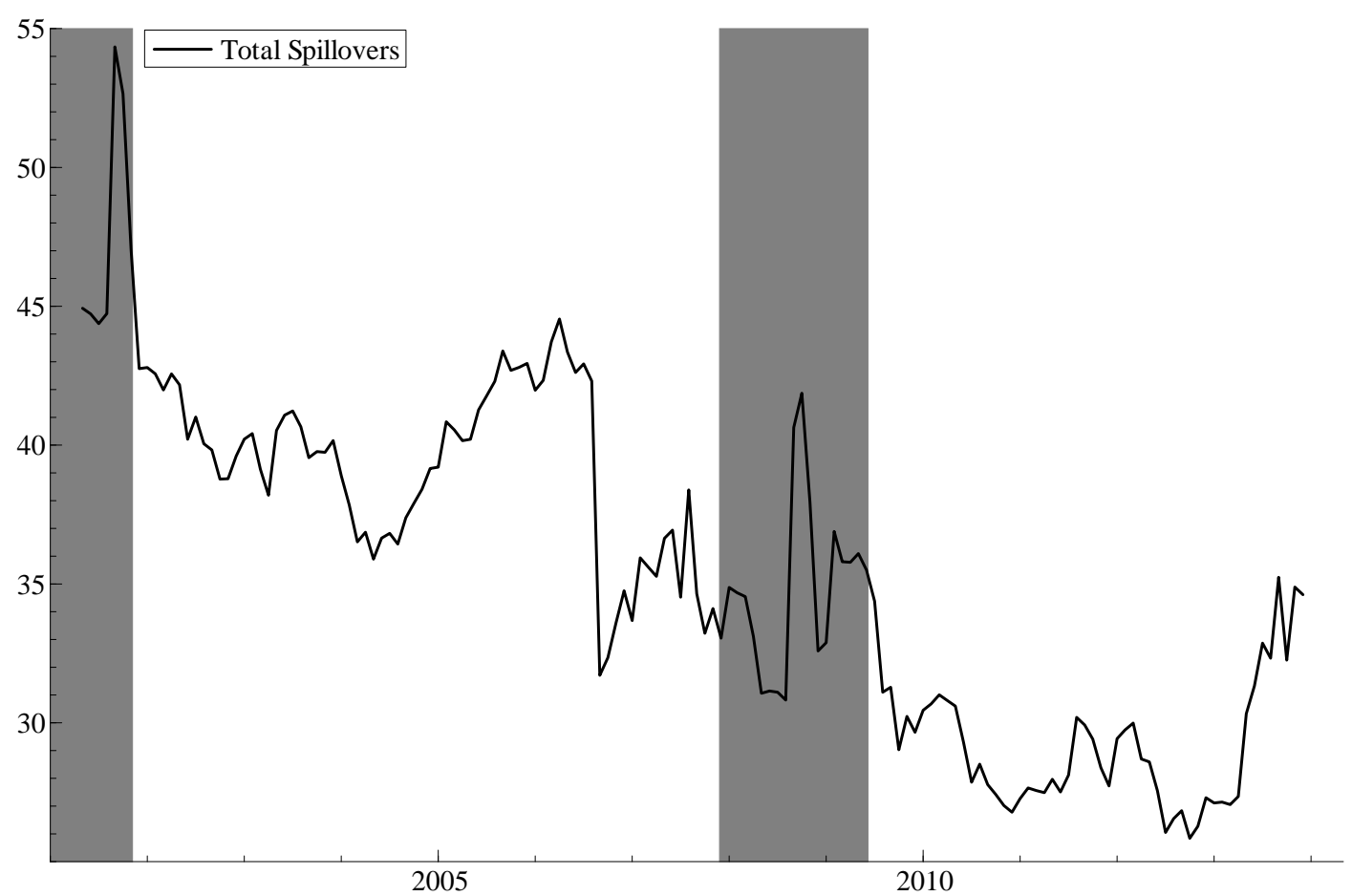

Note: Shading areas denote US recessions as defined by NBER. The total spillover index is calculated based on 12-months step-ahead forecast error variance decomposition. 
Figure 3: Directional spillovers FROM all other variables TO outbound tourism demand using 60-month rolling window. Sample runs from 2001:1 - 2013:12.



Note: Shading areas denote US recessions as defined by NBER. The directional spillover index is calculated based on 12-months step-ahead forecast error variance decomposition. 
Figure 4: Net pairwise spillovers using 60-month rolling window. Sample runs from 2001:1 $-2013: 12$.
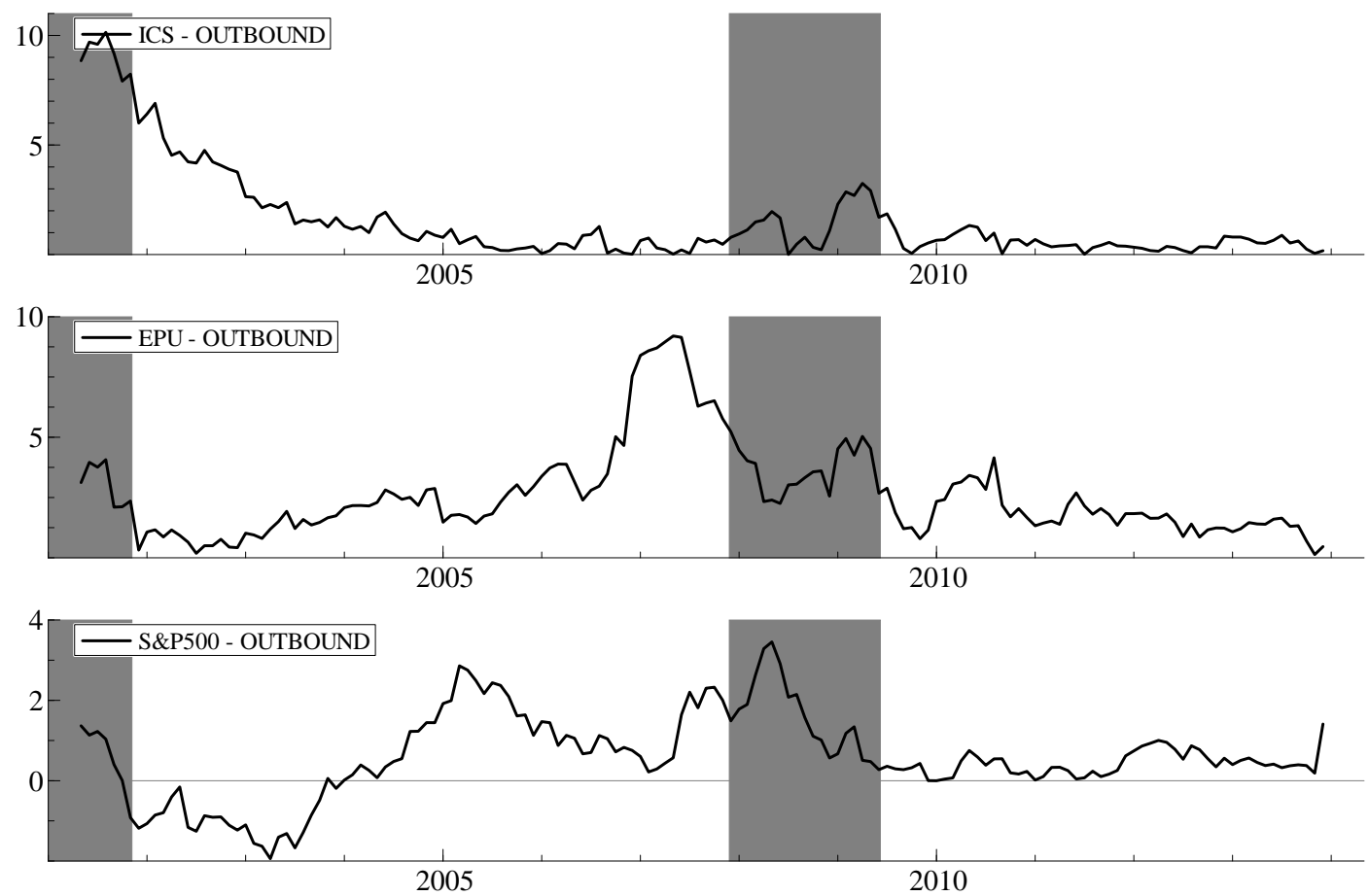

Note: Shading areas denote US recessions as defined by NBER. The OUTBOUND is a net receiver (transmitter) of spillover shocks when the lines are above (below) zero. The net pairwise spillover indices are calculated based on 12-months step-ahead forecast error variance decomposition. 